Os direitos autorais dos trabalhos aceitos para publicação serão cedidos para a Revista de Economia e Administração. Será permitida sua reprodução total ou parcial desde que citada a fonte. O conteúdo dos artigos submetidos são de responsabilidade exclusiva dos autores, permanecendo sua responsabilidade mesmo depois da transferência do direito de reprodução.

The copyright of papers accepted for publication will be granted to the Revista de Economia e Administração. Will be allowed a total or partial reproduction provided the source is cited. The content of submitted articles are solely the responsibility of the authors and remain your responsibility even after the transfer of the right of reproduction.

Fonte: http://seer.insper.edu.br/index.php/rea/about/submissions\#copyrightNotice. Acesso em: 24 out. 2013. 


\title{
Gestão de custos na administração pública: estudo de casos do governo da Bahia e do Banco Central do Brasil
}

\author{
Hong Yuh Ching \\ Chefe de Depto. de Administração do Centro Universitário FEI \\ Doutor em Engenharia pela Unicamp e Mestre em Ciências Contábeis pela \\ PUC/SP \\ Rua Gil Eanes, 409, apto 21, Campo Belo \\ CEP: 04601-041 São Paulo - SP Brasil \\ e-mail: hongching@fei.edu.br
}

\section{Henrique Flavio Rodrigues da Silveira}

Analista de Orçamento e Custos, Banco Central do Brasil

Doutor e Mestre em Ciência da Informação

Setor Bancário Sul - Quadra 3 - Bloco B - Edifício Sede - 9º andar

CEP: 70074-900 Brasília - DF Brasil

e-mail: Henrique.Silveira@bcb.gov.br

\section{Fátima de Souza Freire}

Professora Associada, Universidade de Brasília (UNB)

Doutora e Mestre em Economia

Prédio da FACE, s. B1-02, Campus Universitário Darcy Ribeiro

CEP: 70910-900 Brasília - DF Brasil

e-mail: ffreire@unb.br

\begin{abstract}
Resumo
Alguns fatores, entre eles a edição da Lei de Responsabilidade Fiscal (LRF) e novos instrumentos de gestão, migrados do setor privado, têm motivado empresas e órgãos do setor público no Brasil a adotarem uma nova gestão dos recursos públicos e de avaliação dos seus resultados. Esse artigo tem como objetivo relatar as experiências com a implantação de um sistema de custos pelo Governo da Bahia e pelo Banco Central do Brasil, seus diferentes formatos, análises e relatórios produzidos. A metodologia utilizada foi a do estudo de caso com relato das etapas envolvidas, benefícios esperados e resultados alcançados, bem como das dificuldades encontradas. As análises conduzidas nesse artigo indicam que os aperfeiçoamentos que aumentem a utilização gerencial do sistema de custos e a aderência do sistema ao plano teórico não são apenas possíveis como são necessários. A contribuição desse artigo é demonstrar como vem sendo implantado o sistema de custos em organizações públicas em geral no Brasil e, em particular, nas duas organizações objeto desse artigo. O relato desses dois casos não deve ser visto apenas como forma de compartilhar seus resultados, mas também como oportunidade de oferecer a outras organizações públicas, em qualquer esfera governamental, motivação e informações para o empreendimento de ações semelhantes.
\end{abstract}

Palavras-chave: Lei de Responsabilidade Fiscal; Contabilidade pública; Custeio baseado em atividade; Sistema de custo. 
Gestão de custos na administração publica: estudo de casos do governo da Bahia e do Banco Central do Brasil

\begin{abstract}
Some factors, like the Fiscal Responsibility Law (LRF) and new management tools originally developed in the private sector, have motivated state-owned companies and government agencies in Brasil to adopt a new approach to the management of public resources and the assessment of their performance. This article reports two cases in public administration - at the Bahia State Government and the Central Bank of Brasil - of the implementation of a cost accounting system. The case study method was used for reporting the steps involved, benefits expected and results achieved, as well as the difficulties met. The analyses conducted in this article indicate that the enhancements for improving the managerial uses of the cost accounting system and its adherence to the theory are not only possible, but necessary. The contribution of this article is to demonstrate the implementation of the cost accounting system in the public sector in general in Brasil and, in particular, at the Bahia State Government and the Central Bank of Brasil. The reporting of these two cases must not be seen only as a way of sharing their results, but also as an opportunity for offering to other public organizations, at any government level, the motivation and information necessary for taking similar actions.
\end{abstract}

Keywords: Fiscal responsibility law; Government accounting; Activity-based cost accounting; Cost accounting system.

\title{
1. Introdução
}

A importância das informações sobre os custos governamentais não se resume à contribuição que elas podem dar para a eficiência e a eficácia do gasto público, mas também pelo que representam à luz da necessidade de ser promovida uma profunda reforma da gestão pública no país (REZENDE; CUNHA; CARDOSO, 2010). Nessa linha, a edição da Lei Complementar nº101/2000 (BRASIL, 2000), intitulada Lei de Responsabilidade Fiscal (LRF) pode ser considerada um divisor de águas na administração pública. Ela estabelece normas de finanças públicas voltadas para a responsabilidade na gestão fiscal, mediante ações em que se previnam riscos e corrijam desvios capazes de afetar o equilíbrio das contas públicas, destacando-se o planejamento, o controle, a transparência e a responsabilização. Essa lei cria condições para a implantação de uma nova cultura gerencial na gestão dos recursos públicos e incentiva o exercício pleno da cidadania, especialmente no que se refere à participação do contribuinte no processo de acompanhamento da aplicação dos recursos públicos e avaliação dos seus resultados. Impactos produzidos por essa lei nos orçamentos municipais foram relatados por Santana et al. (2007), Santos e Alves (2007) e Toneto e Menezes (2006).

Por outro lado, o Tribunal de Contas da União (TCU), por meio do Acórdão $n^{\circ}$ 1.078/2004 (BRASIL, 2004), determinou que a administração pública federal disponha de sistemas de custos, permitindo a avaliação e o acompanhamento da gestão orçamentária e financeira de responsáveis, seguindo o disposto na Lei de Responsabilidade Fiscal, Lei Complementar $n^{\circ} 101 / 2000$, art. 50, § $3^{\circ}$, (BRASIL, 2000) na LDO Lei de Diretrizes Orçamentárias para 2003, Lei $n^{\circ}$

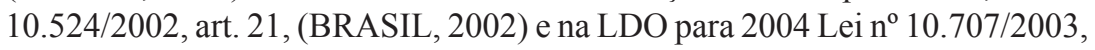
art. 20, $\S 2^{\circ}$ (BRASIL, 2003). Esses dispositivos legais representaram o embasamento que impulsionou, definitivamente, o processo de desenvolvimento e 
implantação de um sistema de custos no Governo da Bahia e no Banco Central do Brasil (2004).

Outro fator motivador é a tendência crescente de imprimir no setor público, cada vez mais, os princípios gerenciais de eficácia, eficiência e avaliação de resultados. As empresas e os órgãos do setor público têm procurado adotar práticas de administração do setor privado, e uma variada gama de instrumentos de gestão vem sendo incorporada pelos gestores públicos a fim de dotá-los de maior capacidade gerencial. As instituições públicas têm aperfeiçoado seus processos (BIAZZI et al., 2006) e programas públicos estão sendo avaliados com o uso de mapas estratégicos e o Balanced Scorecard (NETO, MELO, PEREIRA, 2006). O Banco Central do Brasil, em Banco Central do Brasil (2004, p. 8) refere-se a um novo termo, denominado "nova administração pública" - new public management - para descrever uma tendência global em direção a um certo tipo de reforma administrativa, contribuindo para a elaboração de uma visão mais econômica e gerencial da administração governamental.

Para Rezende, Cunha e Cardoso (2010) o foco em resultados, a ampliação da transparência das ações governamentais, o aumento da accountability de políticos, gestores e profissionais na administração pública, assim como a identificação de novas formas de provisão dos serviços públicos têm na informação de custos um de seus pilares fundamentais. A idéia motivadora para a implantação de qualquer sistema de custos na área governamental deve estar sempre em consonância com as seguintes dimensões fundamentais de fornecimento dos serviços públicos (BANCO CENTRAL DO BRASIL 2004, p.7):

- Planejamento - constitui a fase de elaboração das estratégias em que tem lugar a definição dos objetivos do serviço a ser prestado;

- Orçamento - fase em que são alinhadas todas as atividades e todos os projetos, mediante as diversas variáveis identificadoras do serviço;

- Gestão - fase em que se destaca a importância da administração em relação à especificação de objetivos e na qual deve existir clara separação entre a esfera política - própria da administração - e a técnico-econômica da organização.

Por fim, são várias as dificuldades na implantação de um sistema de custos na administração pública. Seja pela ocorrência de informações em duplicidade, em que Silva et al. (2008) salientam que, em algumas situações, um mesmo gasto pode envolver atividades exercidas por mais de uma unidade e um mesmo gasto pode envolver fases em departamentos distintos. Ou pela falta de incentivo e/ou ao surgimento de fatores inibidores à utilização das informações geradas pelo sistema de custos, ou ainda porque as informações indicadas não atendem à demanda (WERNECK, 2006).

O objetivo desse artigo é relatar as experiências com a implantação de um sistema de custos pelo Governo da Bahia e pelo Banco Central do Brasil, e com isso oferecer a outras organizações públicas informações para o empreendimento de ações semelhantes. 
Gestão de custos na administração publica: estudo de casos do governo da Bahia e do Banco Central do Brasil

\section{Referencial teórico}

\subsection{Formação do marco regulatório do sistema e controle de custos no setor público}

A preocupação com a contabilidade de custos na administração pública tem como marco inicial a lei $\mathrm{n}^{\circ} 4.320 / 1964$ (BRASIL, 1954), que trata das normas de elaboração e controle dos orçamentos e balanços da União, dos estados, municípios e do Distrito Federal. Nos seus artigos 85 e 99 ela determina:

Artigo 85: Os serviços de contabilidade serão organizados de forma a permitirem o acompanhamento da execução orçamentária, o conhecimento da composição patrimonial, a determinação dos custos dos serviços industriais...

Artigo 99: Os serviços públicos industriais, ainda que não organizados como empresa pública ou autárquica, manterão contabilidade especial para determinação dos custos, ingressos e resultados, sem prejuízo da escrituração patrimonial e financeira comum.

A seguir, o Decreto-Lei no 200/1967 (BRASIL, 1967) dispôs sobre a nova organização da administração pública e também tratou do tema custos no seu artigo 79: "A contabilidade deverá apurar os custos dos serviços de forma a evidenciar os resultados da gestão".

O Decreto $\mathrm{n}^{\circ}$ 92.452/1986 (BRASIL, 1986) criou a Secretaria do Tesouro Nacional com o objetivo de auxiliar o Ministério da Fazenda na execução de um orçamento unificado. No seu artigo $137, \S 1^{\circ}$, ela determina:

"A apuração do custo dos projetos e atividades terá como base os elementos fornecidos pelos órgãos de orçamento, constantes dos registros do Cadastro Orçamentário de Projeto/Atividade, a utilização dos recursos financeiros e as informações detalhadas sobre a execução física que as unidades administrativas gestoras deverão encaminhar ao respectivo órgão de contabilidade, na periodicidade estabelecida pela Secretaria do Tesouro Nacional."

Outro grande marco regulatório foi a lei complementar $n^{\circ}$ 101/2000 (BRASIL, 2000), também conhecida como Lei de Responsabilidade Fiscal (LRF). Ela impõe legalmente a necessidade de um sistema de custos conforme seus $\operatorname{artigos} 4^{\circ}$ e 50 :

Artigo $4^{\circ}:$ A lei de diretrizes orçamentárias atenderá o disposto no $\S 2^{\circ}$ do art. 165 da Constituição e:

I - disporá também sobre:

(...) 
e) normas relativas ao controle de custos e à avaliação dos resultados dos programas financiados com recursos dos orçamentos;

Artigo 50, § $3^{\circ}$ : A Administração Pública manterá sistema de custos que permita a avaliação e o acompanhamento da gestão orçamentária, financeira e patrimonial.

Em 2004, o TCU também se manifestou a respeito do sistema de custos, pelo Acórdão n ${ }^{\circ}$ 1078/2004 - 2 ${ }^{\mathrm{a}}$ Câmara (BRASIL, 2004), determinando à Secretaria de Orçamento Federal (SOF) que adotasse providências para que a administração pública federal pudesse dispor de sistema de custos que permita a avaliação e o acompanhamento da gestão orçamentária e financeira responsáveis. No mesmo ano, em relatório sobre as contas do Governo da República, o TCU recomendou ao Ministério de Planejamento, Orçamento e Gestão (MPOG) que adotasse providências com vistas ao estabelecimento de sistema de custos para avaliação e acompanhamento da gestão orçamentária, financeira e patrimonial de que trata o $\S 3^{\circ}$ do art. 50 da LRF.

Em 2005 foi constituída a Comissão Interministerial de Custos, (MINISTÉRIO DO PLANEJAMENTO, ORÇAMENTO E GESTÃO, 2006) através da Portaria Interministerial $n^{\circ} 945$ (BRASIL, 2005) com objetivo de elaborar estudos e propor diretrizes, métodos e procedimentos para subsidiar a implantação do sistema de custos na Administração Pública Federal (APF).

Em 2009, o Decreto $n^{\circ}$ 6.976/2009, no seu art. $3^{\circ}$ (BRASIL, 2009) dispôs sobre o sistema de contabilidade federal, cuja finalidade, utilizando as técnicas contábeis, seria registrar os atos e fatos relacionados com a administração orçamentária, financeira e patrimonial da União e evidenciar:

VI - os custos dos programas e das unidades da administração pública federal;

No mesmo ano, o TCU voltou a se manifestar (Acórdão n 3895 - $1^{\text {a }}$ Câmara). Ele determinou ao MPOG e ao Ministério da Fazenda, ao qual se subordina o órgão central do sistema de contabilidade federal, que apresentassem, em 90 dias a partir da publicação do Acórdão, uma programação, com duas datas e pontos de controle de implantação da operacionalização do sistema de custos da Administração Pública Federal, de que trata o $\S 3^{\circ}$ do art. 50 da LRF.

\subsection{Algumas ações realizadas pelo Poder Executivo Federal}

No seu relatório final de junho de 2006, a Comissão Interministerial de Custos (MINISTÉRIO DO PLANEJAMENTO, ORÇAMENTO E GESTÃO, 2006) apontou os diversos benefícios com a implantação do sistema de custos e fez algumas recomendações para a adoção desse sistema pelos órgãos públicos. 
Gestão de custos na administração publica: estudo de casos do governo da Bahia e do Banco Central do Brasil

Benefícios com a implantação do sistema:

- Otimização dos resultados dos programas governamentais.

- Maior qualidade e transparência do gasto público.

- Redução do desperdício.

- Aprimoramento da qualidade do produto oferecido ao cidadão.

- Aperfeiçoamento da gestão pública.

- Melhor desempenho institucional.

Diretrizes recomendadas para a adoção do Sistema de Informações Fiscais (SIF) pela APF:

- Gestão de custos com foco no resultado.

- Abrangência.

- Gradualismo.

- Flexibilidade.

- Institucionalização.

- Capacitação permanente.

Algumas recomendações:

- Projeto de lei para criação de cargos em níveis setoriais e seccionais da estrutura do Sistema de Custos.

- Criação do sítio Custos Governamentais.

- Convênio/parceria com a ABC e Acordos de Cooperação Técnica Internacional.

- Contratação de consultoria.

- Plano de capacitação de servidores.

- Elaboração do Manual de Custos do PEF.

Em atendimento à portaria da Secretaria de Orçamento Federal (SOF) 68/07, o Poder Executivo Federal criou a Câmara Técnica da Qualidade do Gasto. Essa Câmara realizou as seguintes atividades:

- Deu continuidade aos trabalhos da Comissão Interministerial.

- Realizou treze debates semanais sobre qualidade dos gastos públicos.

- Apresentou, em setembro de 2008, consolidação dos trabalhos realizados pela Câmara, apresentando orientações para o desenvolvimento e a implantação de metodologias e sistemas de geração e emprego de informações de custos no governo federal.

Quanto ao desenvolvimento do Sistema de Informações de Custos na Administração Pública Federal, os trabalhos foram iniciados em 15/04/09, a partir do Relatório da Comissão Interministerial anteriormente citada, 
dos trabalhos realizados pela Câmara Técnica da Qualidade do Gasto, e de pesquisa realizada pela Secretaria Executiva do Ministério da Fazenda acerca de Custos na Administração Pública. Um sistema foi desenvolvido pelo SERPRO, com informações geradas pelo SIAFI, pelo SIAPE e pelo SIGPLAN, utilizando-se um Data Warehouse. Dois marcos importantes de acompanhamento foram:

- 30/12/2009: apresentação da modelagem inicial do Sistema, com vistas à homologação pelo Ministério da Fazenda.

- 01/06/2010: apresentação oficial e final do Sistema de Custos.

Por fim, o Ministro da Fazenda afirma que a partir da efetivação do Sistema de Informação de Custos pelo Governo Federal, em março de 2010, as condições para mudança foram efetivamente potencializadas. Agora se faz necessário aumentar o debate sobre mensuração de custos e destacar sua importância para a melhoria da qualidade do gasto no setor público (HOLANDA; LATTMAN-WELTMAN; GUIMARÃES, 2010).

\subsection{Classificação das despesas públicas e a estrutura programática}

As despesas públicas podem ser classificadas quanto à natureza e quanto à função. A classificação funcional das despesas, compostas de um rol de funções e sub-funções pré-fixadas, exerce o papel de agregador dos gastos públicos por área de ação governamental, nas três esferas. Trata-se de uma classificação independente dos programas. As funções são as ações desenvolvidas pelo Governo, reunidas em seus grupos maiores como: Legislativa, Agricultura, Transportes, etc. Por outro lado, as sub-funções visam a agregar determinado conjunto de despesas do setor público e identifica a natureza básica das ações que se aglutinam em torno das funções (LIMA; CASTRO 2000, p. 57 e 58). Por exemplo, na função Transporte, teremos as sub-funções Transporte Aéreo, Transporte Rodoviário, Transporte Ferroviário, etc.

Para Lima e Castro (2000), o modelo da estrutura programática, que substituiu a classificação funcional programática, está baseado na utilização dos Programas como módulo integrador entre planejamento e orçamento, em que cada programa deverá dar solução a um problema, mediante conjunto articulado de projetos, atividades e ações. Dessa forma, o programa é o instrumento de organização da atuação governamental. Exemplos de programas são a defesa dos direitos da criança e do adolescente, a segurança nas rodovias federais, a qualidade e eficiência do SUS. O projeto é um instrumento de programação para alcançar o objetivo de um programa, envolvendo um conjunto de operações limitadas no tempo. Atividade é instrumento de programação envolvendo um conjunto de operações que se realizam de modo contínuo e permanente. Um exemplo de codificação funcional e programática seria: 
Gestão de custos na administração publica: estudo de casos do governo da Bahia e do Banco Central do Brasil

\author{
Função: Transporte \\ Sub-Função: Transporte Rodoviário \\ Programa: Segurança nas rodovias federais \\ Projeto/Atividade: Manutenção da sinalização rodoviária
}

O controle de custos deve ser estruturado de maneira a fornecer respostas aos questionamentos dos gestores públicos quanto à origem e ao destino de cada gasto. Os sistemas de custeio são desenvolvidos para medir e atribuir valores ao objeto de estudo.

Observa-se que as empresas privadas apropriam os custos aos produtos ou serviços por meio da escolha entre diversos sistemas abordados na literatura, tais como: custeio por absorção; custeio integral ou RKW; custeio variável; custeio padrão; unidade de esforço de produção e custeio baseado em atividades. Alguns destes métodos são aceitos pelo fisco por atender princípios de contabilidade e legislações pertinentes à apuração de custos, como é o caso do método de custeio por absorção, que incorpora custos diretos e indiretos a todos os produtos, seguindo principalmente os princípios da competência e da consistência.

Para Machado e Holanda (2010), a escolha do método de custeio do setor público não é tarefa fácil, por existirem defensores para quase todos os métodos. Por não haver limitação legal quanto ao uso dos métodos de custeio, qualquer método pode ser adotado. Eles apresentam argumentos em defesa do custeio direto e do custeio por atividades no setor público. Vale ressaltar que as formas de contabilizar e apropriar os gastos, no setor público, são completamente diferentes daquelas adotadas por uma empresa privada, pois parte dos gastos públicos é registrada pelo regime de caixa e outra parte pelo regime de competência. Isto dificulta substancialmente a escolha de um método para fins gerenciais, ou seja, para atender demanda de informações para algum órgão público. Numa entidade pública, na apuração do valor do seu principal objeto de custeio os desafios são grandes, mas não impossíveis. Para a apuração do custo de um serviço ou produto, é necessário definir os itens que o compõem, o que não consiste numa simples tarefa contábil, uma vez que estas instituições desenvolvem um conjunto de atividades complexas, com características locais e regionais, específicas a cada órgão.

Hoje existe uma preocupação ampla quanto à aplicação de sistemas de custos no setor público, tais como: diretrizes e modelo conceitual de custos aplicados ao governo (MACHADO; HOLANDA, 2010); informações de custos para a tomada de decisão (PIGATTO et al., 2010); eficácia e accountability (SLOMSKI et al., 2010).

\title{
2.4 Aplicações de sistema de custos no setor público
}

Embora na legislação brasileira existam preocupações quanto à necessidade de implantação de sistemas de custo na administração pública, observa-se que as experiências nos órgãos são poucas ou inexistentes. Silva e Rocha (2009) 
relatam que o Comando da Aeronáutica, o Comando da Marinha, o Comando do Exército, a Empresa Brasileira de Correios e Telégrafos, o Banco Central do Brasil e a EMBRAPA são as poucas entidades públicas brasileiras a empregarem ainda de forma específica algum tipo de sistema de custos. Silva et al. (2008) descrevem as dificuldades para a implantação de um sistema de custos no Departamento de Planejamento Econômico da Secretaria Municipal de Planejamento de Feira de Santana (BA).

Poucas também são as experiências descritas na literatura com implantação do custeio ABC no setor público. Raupp (2010) elaborou uma proposta de aplicação do ABC na Legislativo do Município de Paulo Lopes, em Santa Catarina. Essa implantação permite analisar os custos departamentais, os custos das atividades desenvolvidas pelos agentes, bem como o custeamento das diferentes matérias. Apesar da filosofia do $\mathrm{ABC}$ de intentar para a eliminação de critérios de rateio, o autor não conseguiu rastrear os itens de gastos contemplados na conta "gastos gerais". Embora essa realidade seja de um município de pequeno porte, Raupp (2010) acredita que a sua estrutura possa ser implantada em legislativos de municípios de maior porte. Werneck (2006) também relata a experiência do Banco Central do Brasil com o sistema ABC examinando, no entanto, os desdobramentos ocorridos a partir da sua implantação. Ela sustenta que, pelo fato do $\mathrm{ABC}$ explorar as especificidades de cada instituição, adaptando-se às mais diversas realidades, sua aplicação seria válida para o setor público.

Holanda, Lattman-Weltman e Guimarães (2010) argumentam que se abre uma "janela de oportunidade" para a efetivação do Sistema de Informações de Custo do Governo Federal (SIC). Este passa a se constituir como uma ferramenta importante para a difusão do próprio conhecimento acerca da máquina pública, suas regras e formas de ação. Para eles, a informação que mais efetivamente conta é quanto custam os serviços, atividades e produtos prestados por nossos poderes públicos. Machado e Holanda (2010) apresentam um modelo teórico-conceitual de custos para o setor público e as diretrizes que sustentaram a sua concepção a partir do SIC.

Com a implantação paulatina desse sistema, espera-se que mais experiências possam ocorrer no setor público e sejam descritas na literatura.

\section{Estudo de casos}

\subsection{Governo do Estado da Bahia}

\subsubsection{Histórico e objetivos estabelecidos}

Mesmo antes da edição da Lei de Responsabilidade Fiscal, o desenvolvimento de um sistema para a apropriação de custos tinha sido objeto de interesse da área financeira do Estado. Para fins de programação financeira, tentou-se extrair índices de correlação entre um investimento realizado e os seus gastos de manutenção, recorrendo-se aos dados contabilizados. A base de dados, constituída para atender 
Gestão de custos na administração publica: estudo de casos do governo da Bahia e do Banco Central do Brasil

aos dispositivos da Lei 4320/64, mostrava-se imprópria para essa extração, bem como para elaborar um sistema que objetivasse a aferição de custos do setor público. Outra dificuldade era a de que a nomenclatura adotada pela Contabilidade Pública, em que pese seus méritos inquestionáveis, não oferece ao gestor público a facilidade de uma rápida leitura e análise da vasta gama de dados existentes.

Com a promulgação da LRF, surgiu a necessidade de disponibilizar para o Estado um sistema de custos que permitisse um gerenciamento eficaz e sistemático da utilização dos seus recursos.

O objetivo primeiro desse sistema foi o de atender à LRF; em segundo lugar, avaliar os custos do Estado em diversas unidades administrativas, ações, produtos e serviços; em terceiro lugar, atender às demandas específicas de cada Secretaria. Os benefícios esperados para esse sistema foram definidos como sendo: gerenciamento dos custos de cada unidade funcional pelos respectivos gestores; identificação dos custos de cada serviço público e das atividades inerentes aos mesmos; possibilidade de análises quanto a relações de custo e benefício e avaliação da qualidade dos gastos; criação de uma base de dados para a extração de correlações entre os investimentos e sua respectiva manutenção; produção de dados para a construção de indicadores de desempenho; subsídios para elaboração de orçamentos e controle.

\subsubsection{Organização e etapas do projeto do sistema de custos}

Optou-se por desenvolver um projeto piloto para a apropriação de custos nas Secretarias da Fazenda, da Administração e do Planejamento, que posteriormente fosse estendido às demais secretarias do Estado.

Para tanto, foi constituído um Comitê Central no $2^{\circ}$ semestre de 2001 para a concepção do sistema em sua visão macro, liderado pela Secretaria da Fazenda, com as participações das de Administração e Planejamento. Ao Comitê respondiam um gestor do projeto (um profissional da Fazenda) e três Comitês Setoriais, um para cada Secretaria, formados pelas Diretorias de Orçamento e suas respectivas equipes de trabalho. Por fim, criou-se uma equipe de desenvolvimento, em período integral, constituída por cinco pessoas com a função de interagir com as equipes setoriais. Uma consultoria externa foi contratada para a concepção, modelagem e implantação desse sistema e reportando-se ao Comitê Central.

As seguintes etapas foram realizadas na consecução desse projeto, que durou um ano:

1. Definir as unidades funcionais ou de custo para efeitos de apuração e controle de custos.

2. Definir os itens de custos relevantes para controle nas unidades funcionais, relacionando-os com a classificação funcional programática.

3. Conceituar e descrever as contas contábeis - agrupar as contas contábeis de gastos em categorias de controle de natureza afim, quando necessário, e descrever em que consiste cada categoria de controle. 
4. Identificar a base de informações (internas ou externas às Secretarias) dos itens de custos junto aos responsáveis das áreas funcionais. Existiam controles para todos os itens de custo, porém com predominância de soluções "domésticas" e formas manuais. Nessa etapa, buscou-se integrar e padronizar os sistemas existentes - os chamados "sistemas periféricos", que alimentariam o sistema de custos; criar novos sistemas em substituição aos controles manuais e às soluções domésticas.

5. Desenvolver o software do sistema de custos - implantar inicialmente as adequações necessárias e/ou criar sistemas auxiliares ao sistema de custos para apropriar todas as informações referentes aos itens de custos às diversas Unidades Funcionais. Em seguida, o pessoal da Tecnologia de Informação iniciaria a modelagem desse software e realizaria pré-testes de lógica.

6. Montar modelo de relacionamento (em duas dimensões) das Unidades Funcionais ou de custo versus itens de custo.

7. Testar e homologar o sistema de custos - sistema de custos rodando e atendendo os objetivos inicialmente traçados no modelo de duas dimensões.

8. Identificar as macro-atividades das Unidades Funcionais (fim e meio) e seus respectivos direcionadores de custos.

9. Montar modelo de relacionamento (em três dimensões) das Unidades Funcionais versus Itens de Custos versus Atividades - com isso, seria permitido aos gestores saberem quanto, quem, o que e como estaria sendo gasto em cada Unidade Funcional.

10. Testar e homologar o sistema de custos no modelo de três dimensões.

O Sistema de Custos do Governo da Bahia foi oficialmente batizado de Apropriação de Custos Públicos (ACP).

\subsubsection{Visão geral do ACP}

A finalidade do Sistema de Custos é responder a três perguntas: o que se gasta, quem gasta e como se gasta? Para responder a essas perguntas há uma hierarquização de conceitos desenhada no ACP e uma relação com os conceitos da contabilidade pública. Uma visão do ACP pode ser encontrada na Figura 1.

Trabalhou-se com uma nomenclatura "alternativa" à Contabilidade Pública no ACP, porém não desvinculada da mesma. A seguir, são apresentados os conceitos-chave utilizados, distinguindo-os dos conceitos habituais empregados no serviço público.

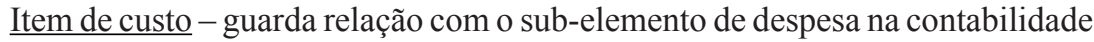
pública. Visa a responder o que se gasta e identifica o consumo dos recursos postos à disposição do gestor. Ele é identificável na base de dados através de quatro vetores ou coordenadas: a) código do sub-elemento (extraído do SICOF - Sistema de Informações Contábeis e Financeiras); b) código de unidade de 
Gestão de custos na administração publica: estudo de casos do governo da Bahia e do Banco Central do Brasil

Figura 1.- Visão geral do $A C P$.

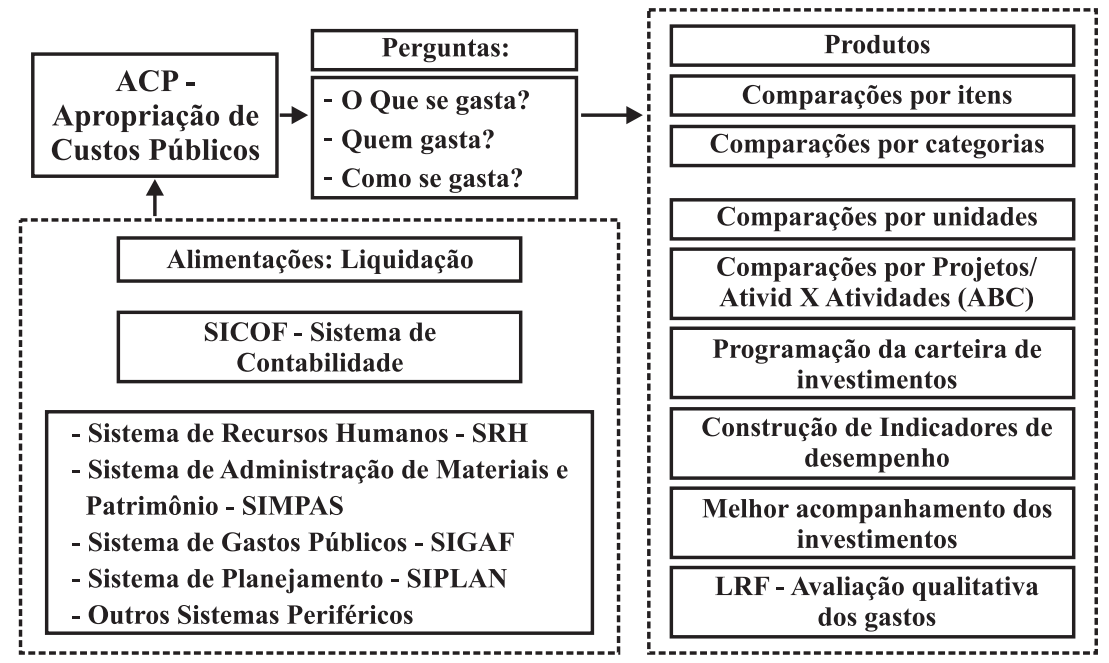

custo (extraído do SRH - Sistema de Recursos Humanos); c) código do Projeto/ Atividade (extraído do SIPLAN - Sistema de Planejamento); d) ano e mês de referência. Alguns exemplos são: remuneração de pessoal contratado, limpeza e conservação, impostos e taxas, energia, pensão, condomínios, etc. No total, 109 itens foram considerados nesse sistema.

Categoria de custo - guarda relação com o elemento de despesa na contabilidade pública. No entanto, na funcional programática da Lei nº 4.320/1964 (BRASIL, 1964), os sub-elementos se encontram agregados por elementos de despesa, não facilitando a sua transparência e o seu controle. No ACP, os itens de custo são agregados segundo a semelhança da despesa, por categoria. Foram criadas nove categorias: administrativo, material permanente, deslocamentos, publicidade, informática, recursos humanos, locações, transporte e material de consumo. Para ilustração, na categoria administrativo, os itens de custo seriam limpeza e conservação, energia, água e correios.

Unidade funcional ou de custo - guarda relação com a unidade administrativa na contabilidade pública. Compreende quem gasta. São unidades que acumulam gastos, e o objetivo é medir o custo de todas as Unidades formalmente previstas no Regimento Interno de cada secretaria. O ACP pretende conferir a cada Unidade a feição de centro de responsabilidade. Pode ter vários níveis, conforme definidos por cada Secretaria para efeitos de controle. Assim, uma exemplificação na Secretaria da Fazenda poderia ser: Secretaria ( $1^{\circ}$ nível $)$, Superintendência ( $2^{\circ}$ nível), Diretoria ( $3^{\circ}$ nível), Gerência ( $4^{\circ}$ nível), Inspetoria (5 nível), Posto Fiscal (6 $6^{\circ}$ nível). 


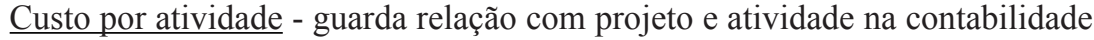
pública. Sob a ótica do serviço público, projeto difere de atividade quanto à sua continuidade ao longo do tempo para alcançar um objetivo, mas na essência ambos se referem à ação concreta da Administração Pública no desempenho de suas funções. Sob a ótica do custeio baseado em atividades, as atividades dizem respeito às ações necessárias para a consecução de um processo e objetivam responder à seguinte pergunta: "O que as pessoas fazem numa organização? Elas fazem atividades que consomem recursos para produzir um output" (CHING, 2006, p. 93). O custeio por atividades visa a responder como os recursos são gastos. Assim, o custo da merenda escolar seria a soma das seguintes atividades: aquisição dos gêneros da merenda escolar; distribuição de gêneros da merenda escolar; preparo da merenda escolar, e distribuição da merenda escolar.

Uma regra mantida na elaboração do ACP foi a de não ratear despesas entre unidades de custo. Se uma despesa não puder ser apropriada às unidades, será alocada na unidade responsável pela mesma, seja pela gestão do contrato, seja pelo seu pagamento. O objetivo é a responsabilização direta pela despesa para que cada unidade tenha responsabilidade pelo seu controle. Assim, por exemplo, as despesas com aluguel e condomínio de uma determinada unidade seriam apropriadas na categoria de custo "locações" na unidade de custo da chefia ou supervisão daquela unidade, e jamais rateada entre as unidades de custo subordinadas àquela chefia.

Na Figura 2 pode-se visualizar o modelo de custos de 3 dimensões, mostrando o relacionamento de itens de custo versus unidades de custo versus atividades.

Figura 2.- Matriz de custos de 3 dimensões.

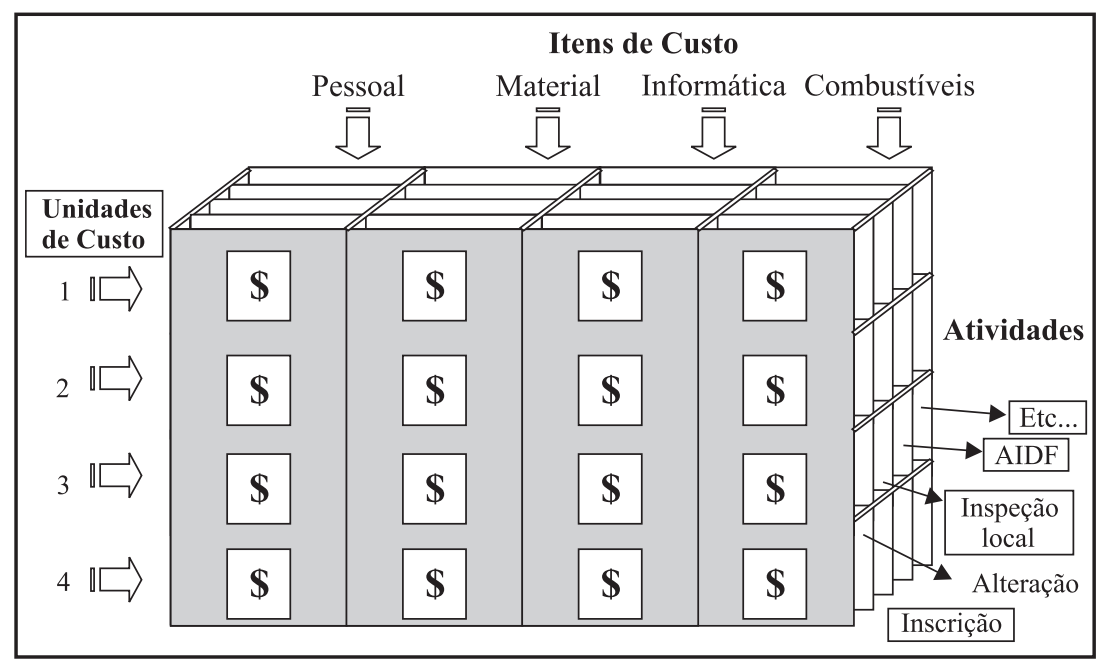


Gestão de custos na administração publica: estudo de casos do governo da Bahia e do Banco Central do Brasil

O ACP foi desenvolvido em plataforma web (internet) para proporcionar fácil acesso aos usuários nos mais diversos níveis da Administração e está integrado com os demais sistemas corporativos do Estado, tais como SICOF, SRH e ICF, para carga de informações.

\subsection{Caso do Banco Central do Brasil (BCB)}

\subsubsection{Histórico e objetivos estabelecidos}

A implantação de um sistema de custos no BCB vinha sendo discutida desde 1992, quando foi objeto de discussão por ocasião da rodada de planejamento estratégico daquele ano. Por questões de ordem técnica, entretanto, a iniciativa não prosperou, sendo o assunto retomado em 1998, novamente por ocasião de outra rodada de planejamento estratégico, quando foram realizados estudos com a colaboração de uma consultoria externa para a definição do escopo do projeto. Com a entrada em vigor da LRF em 2000, e com o decisivo apoio da alta administração, houve a retomada de estudos para o desenvolvimento de um sistema de custos.

Destaque-se que, desde o início, a iniciativa do Banco Central encontrou apoio na existência de dispositivos legais e normativos que determinam a implantação de sistemas de custo em organizações públicas. Além disso, foi apoiada principalmente pela possibilidade de utilização das informações a serem geradas pelo sistema no aperfeiçoamento dos seus processos de trabalho e das ferramentas de gestão, levando em conta os princípios gerenciais de efetividade, eficácia e eficiência.

Assim, o Sistema de Custos e Informações Gerenciais (SCIG) do Banco Central do Brasil foi desenvolvido e implantado entre abril de 2002 e junho de 2003. O SCIG é destinado a apurar os custos de todas as ações (atividades e projetos) desenvolvidas e dos produtos (bens e serviços) gerados. O SCIG permite ainda a apuração dos custos dos macro-processos, bem como dos custos da estrutura organizacional, compreendendo diretorias, unidades, subunidades e gerências regionais.

Foram cinco os objetivos estabelecidos com o sistema: mensurar e controlar os custos administrativos do Banco; quantificar o valor dos serviços oferecidos à sociedade (macro-processos); mensurar o grau de eficiência e eficácia no desempenho de suas funções; subsidiar o planejamento da entidade e auxiliar no controle da sua execução e, finalmente, atender às exigências da LRF.

Os desafios enfrentados por ocasião do desenvolvimento desse sistema decorreram da diversidade de processos de trabalho e do grande número de atividades, bem como das limitações inerentes ao setor público.

\subsubsection{Desenvolvimento do sistema de custos}

No $2^{\circ}$ semestre de 2000, um grupo de trabalho, formado por servidores dos Departamentos de Administração Financeira e de Planejamento e Orçamento, 
elaborou e publicou um relatório indicando o custeio baseado em atividades (ABC) como o mais adequado ao BCB, por possibilitar a alocação das despesas administrativas aos produtos e serviços e permitir a mensuração dos custos que não agregam valor. Para a implantação do projeto, houve a realização de uma concorrência internacional para contratação de uma consultoria externa, com o objetivo de auxiliar no desenvolvimento e na implantação do sistema de custos e informações gerenciais do Banco.

Foram também realizadas apresentações para informação, sensibilização e esclarecimento dos objetivos do projeto e suas fases, para a diretoria e os chefes de unidades, com a intenção de assegurar apoio para o projeto.

Para a implantação da metodologia $\mathrm{ABC}$, foi necessária a identificação dos macro-processos funcionais da instituição, que representam o que é feito para que o Banco Central do Brasil cumpra a sua missão, de "assegurar a estabilidade do poder de compra da moeda e um sistema financeiro sólido e eficiente": formulação e gestão das políticas monetária e cambial; regulamentação e supervisão do sistema financeiro nacional; e administração do sistema de pagamentos brasileiro e do meio circulante. A determinação dos objetos (produtos) que seriam custeados pelo sistema privilegiou os macro-processos finais, sendo que os processos de trabalho dos departamentos e as macro-atividades foram relacionados de forma a terem seus custos direcionados aos macro-processos.

O sistema de custos desenvolvido no BCB possui três módulos: módulo de recursos, módulo de atividades e módulo de objetos de custos.

O módulo de recursos contempla todos os insumos (em sentido amplo) necessários ao desenvolvimento de atividades e projetos da instituição. As informações são provenientes dos vários sistemas do Banco (contabilidade, orçamento, material, patrimônio, recursos humanos, contratos, viagens, etc.).

Para facilitar e tornar mais preciso o processo de alocação dos custos, o módulo de recursos está estruturado em dois grupos. O primeiro grupo contempla os recursos que demandam direcionadores para serem imputados às unidades da estrutura organizacional. No segundo grupo estão os custos diretamente associados às unidades, aos quais são adicionados, por meio dos referidos direcionadores, os custos dos recursos do primeiro grupo.

O módulo de atividades compreende o conjunto de ações (atividades e projetos) identificadas em cada unidade da estrutura hierárquica, às quais são direcionados os custos dos recursos, por meio dos direcionadores de primeiro estágio. Já os custos das ações são direcionados para os diversos objetos de custo, conforme relação de pertinência e vinculação lógica, representados pelos direcionadores de segundo estágio (KAPLAN, COOPER, 1998; NAKAGAWA, 1994). Observe-se a adoção do conceito de projeto para aferição de custos, o que possibilita ao Banco identificar os gastos de ações conjuntas desenvolvidas por áreas distintas de forma temporária. Em suma, pode-se identificar o custo total de cada projeto executado.

O levantamento das atividades das unidades administrativas foi feito a partir de entrevistas com os chefes de todas as unidades e subunidades do Banco. 
Gestão de custos na administração publica: estudo de casos do governo da Bahia e do Banco Central do Brasil

Foram mapeadas 3.488 atividades no total, das quais 890 "únicas", ou seja, existentes apenas em determinada unidade administrativa. As demais atividades identificadas não são peculiares a uma determinada unidade, sendo desempenhadas em mais de um componente administrativo. Como exemplos, podemos citar as atividades de apoio logístico, controle de documentos e processos, etc.

Para o custeio dos objetos de custos, foi estruturado um modelo com quatro níveis, de forma a representar os processos de trabalho das diversas unidades administrativas. Os macro-processos, que representam o que o Banco faz para cumprir sua missão, foram caracterizados como objetos de custo de nível 1. Como objetos de custo de nível 2, foram mapeadas as macro-atividades que compõem os macro-processos, as quais por sua vez foram desdobradas em processos de trabalho corporativos (objetos de custo nível 3). Como objetos de custo nível 4 foram identificados os processos de trabalho de cada unidade administrativa. Assim, os objetos do nível 4 são os mais desagregados, enquanto os objetos de nível 1 são os mais agregados. Vide Figura 3 a seguir.

Figura 3.- Módulo de objetos de custo de 4 níveis.

\begin{tabular}{|c|c|c|c|c|}
\hline & $\begin{array}{l}\text { Processos } \\
\text { unidades }\end{array}$ & $\begin{array}{c}\text { Processos } \\
\text { Bacen }\end{array}$ & $\begin{array}{l}\text { Macro } \\
\text { atividades }\end{array}$ & $\begin{array}{c}\text { Macro } \\
\text { processos }\end{array}$ \\
\hline \multirow[t]{3}{*}{ Atividades } & \multirow[t]{2}{*}{$\begin{array}{c}\text { Objetos } \\
\text { de custo } \\
\text { nível } 4\end{array}$} & \multirow[t]{2}{*}{$\begin{array}{l}\text { Objetos } \\
\text { de custo } \\
\text { nível } 3\end{array}$} & $\begin{array}{c}\text { Objetos } \\
\text { de custo } \\
\text { nível } 2\end{array}$ & $\begin{array}{c}\text { Objetos } \\
\text { de custo } \\
\text { nível } 1\end{array}$ \\
\hline & & & & \\
\hline & & & & \\
\hline
\end{tabular}

Fonte: Banco Central do Brasil (2004, p. 16).

Assim, o fluxo de agregação de custos no modelo desenvolvido observa o seguinte detalhamento:

Recursos $\Rightarrow$ Atividades $\Rightarrow$ Processos das unidades $\Rightarrow$ Processos do Bacen $\Rightarrow$ Macro-atividades $\Rightarrow$ Macro-processos

Para efeito de ilustração, o objeto de custo de nível 1 ("Regulamentação e supervisão do SFN") é desmembrado nos objetos de custo de níveis 2 e 3 (BCB, 2004, p.22).

O plano de comunicação do sistema consistiu na realização de seminários para os diretores, chefes e assessores, além da utilização da intranet e de $e$ - 
Tabela 1.- Desmembramento de objeto de custo.

\begin{tabular}{l|l|l}
\hline Objeto de custo nível 1 & \multicolumn{1}{l}{ Objeto de custo nível 2} & Objeto de custo nível 3 \\
\hline & Regulamentação & $\begin{array}{l}\text { Fundamentação } \\
\text { Regulamentação }\end{array}$ \\
\cline { 2 - 3 } $\begin{array}{l}\text { Regulamentação e } \\
\text { Supervisão do SFN }\end{array}$ & Supervisão & $\begin{array}{l}\text { Supervisão } \\
\text { Processos administ. } \\
\text { Regime especial }\end{array}$ \\
\cline { 2 - 3 } & $\begin{array}{l}\text { Reestruturação do } \\
\text { sistema }\end{array}$ & \\
\hline
\end{tabular}

-mails. A equipe que ficou responsável pela gestão do sistema de custos recebeu treinamento específico na metodologia e nas ferramentas utilizadas, tendo sido realizados outros treinamentos com o conjunto de servidores sobre a extração de informações gerenciais e a utilização do módulo de apontamento de horas.

\subsubsection{Características e especificidades do modelo desenvolvido}

Uma especificidade do modelo adotado pelo Banco é a sistemática de registro mensal, por parte de cada servidor, de como o tempo de trabalho foi utilizado, ou seja, que ações foram desenvolvidas e o percentual do tempo dedicado a cada uma. Também não foi adotada uma remuneração média para alocação dos custos de pessoal, prevalecendo os gastos efetivos de cada componente administrativo com salários, encargos e benefícios.

Uma característica importante do modelo adotado é a adoção da premissa de inexistência de ociosidade ou de utilização integral dos recursos. Com isso, admite-se que todos os recursos custeados são utilizados, na totalidade, pelas ações, as quais, por sua vez, têm seus custos totalmente alocados para os objetos de custos. Ching (2006) e Atkinson et al. (2001) advogam a idéia de que a capacidade não utilizada deve ser calculada à parte e seu custo não deve ser atribuído a produtos produzidos ou clientes servidos durante um período. No entanto, a adoção da premissa pelo Banco levou em conta a inexistência de controles gerenciais objetivos para aferir casos de ociosidade ou utilização excessiva de recursos, em especial no caso de recursos humanos.

Uma especificidade do modelo é a compatibilização do sistema de custos com a contabilidade, medida adotada com a finalidade de assegurar a consistência dos valores apurados pelo Sistema de Custos, os quais devem sempre guardar conformidade com os registros contábeis. Com isso, busca-se evitar que o sistema deixe de contemplar algum gasto na aquisição de recursos. Para tanto, foi necessária a criação de mais cinco objetos de custos de nível 1, adicionalmente aos macro-processos do Banco: Atendimento ao Tesouro 
Gestão de custos na administração publica: estudo de casos do governo da Bahia e do Banco Central do Brasil

Nacional; Administração de fundos e programas; Aposentados; Afastados; Institucional.

Os dois primeiros referem-se ao custo de processos específicos para o atendimento ao Governo Federal. O objeto de custos "Aposentados" contempla os custos com o pagamento de aposentadorias e pensões, além dos custos com o processamento dos benefícios e o atendimento aos beneficiários. O objeto de custos "Afastados" contempla os custos com servidores que estão cedidos a outras organizações, com custo para o Banco, e outros afastamentos regulamentares com custos (capacitação, licença-saúde, etc.).

Já o objeto de custos "Institucional" foi criado para receber os custos para os quais não foi possível encontrar formas de alocação técnica ou economicamente viáveis, bem como aqueles custos relacionados ao atendimento de demandas corporativas, não se vinculando a nenhum objeto de custo em particular. Como o modelo prevê que a alocação apenas se dá quando houver a identificação da relação de consumo, no caso do direcionamento de recursos para atividades, e de relação de pertinência e vinculação lógica, no caso do direcionamento de atividades para objetos de custo, os custos não alocados são agrupados no objeto de custos "Institucional".

É importante destacar que existe um monitoramento permanente dos custos alocados ao objeto de custo "Institucional". Constata-se que, mercê de constante aperfeiçoamento do modelo, e mediante a incorporação de novos sistemas e tecnologias, o percentual de custos representados no referido objeto de custo, em relação ao total, vem apresentando redução sistemática desde a implantação do sistema.

\section{Discussão dos casos apresentados}

Tanto o Governo da Bahia quanto o Banco Central embarcaram na implantação de um sistema de custos com a aspiração de aplicá-lo consistente e coerentemente nas suas organizações. Pode-se afirmar que ambos os projetos despertaram a importância do controle e da análise de custos. Contudo, essa implantação tomou diferentes formatos nas duas organizações. Essa seção compara e contrasta esses diferentes formatos e seus resultados.

Algumas semelhanças nos dois casos foram as seguintes: a) os dois projetos foram pioneiros na administração pública no Brasil; b) iniciaram-se quase no mesmo período - ACP no $2^{\circ}$ semestre de 2001 e BCB em meados do $1^{\circ}$ semestre de 2002; c) ambos têm um alto nível de complexidade, com diversidade enorme de processos de trabalho, produtos, serviços e grande quantidade de atividades; d) o $\mathrm{BCB}$ também tratou projetos como atividades à semelhança do Governo da Bahia.

Algumas diferenças foram: a) o Governo da Bahia optou por um projeto piloto envolvendo as Secretarias da Fazenda, Planejamento e Administração, ao passo que o BCB optou por desenvolver seu sistema de custos para toda a organização, que tem 4700 servidores; b) o BCB fez uso de rateios na apropria- 
ção dos custos, ao passo que no ACP isso não ocorreu. O conceito era o de que cada unidade funcional fosse responsável pelos seus custos; c) trabalhou-se com uma nomenclatura "alternativa" à Contabilidade Pública no $\mathrm{ACP}$, porém não desvinculada da mesma, com novas categorias de custo e unidades funcionais sendo criadas. No BCB, os itens e categorias de custo eram os existentes naquele momento, sem qualquer alteração; d) o BCB focou seu sistema de custos exclusivamente na metodologia $\mathrm{ABC}$, ao passo que no $\mathrm{ACP}$ a preocupação maior foi a de elaborar o modelo de duas dimensões - itens de custo versus unidades de custo. A preocupação com atividades ( $3^{\mathrm{a}}$ dimensão do modelo) ficou para o final do projeto.

Ambos os sistemas de custos mudaram radicalmente, para melhor, a análise dos custos. No modelo de duas dimensões do Governo da Bahia (unidades de custo versus itens de custo), cada Secretaria ( $1^{\circ}$ nível) pode analisar suas despesas por categoria e por unidade funcional que se reporta ao Secretário de um determinado período, ou então analisar o total de despesas por unidade funcional e por mês desse mesmo determinado período. Descendo ao $2^{\circ}$ nível (de Superintendência), essas mesmas análises podem ser feitas: o gestor poderá analisar as despesas da sua Superintendência por categoria de custo aberto por cada unidade que se reporta diretamente a ele, ou então analisar o total de despesas por unidade de custo e por mês. O gestor em qualquer nível funcional pode replicar essas análises.

A Secretaria da Fazenda elaborou uma análise da relação entre arrecadação do ICMS e o custo total de funcionamento de cada inspetoria fazendária e chegou a uma média de $2,5 \%$, indicando que, para cada $\mathrm{R} \$ 100,00$ arrecadados de ICMS, cerca de R $\$ 2,50$ correspondem ao funcionamento da máquina arrecadadora. Portanto, as inspetorias que apresentassem um quociente superior a um determinado percentual seriam objeto de uma análise mais detalhada. Esse é um exemplo de uma apreciação crítica dos números revelados pelo ACP.

No modelo de três dimensões (unidade de custo versus itens de custo versus atividade), as análises podem ser feitas de três maneiras: comparativo dos custos em cada unidade administrativa de uma determinada atividade, aberto por item de custo. Assim, os custos das atividades "fiscalizar empresa" e "conceder inscrição fiscal" poderiam ser comparados entre si nas diversas inspetorias fazendárias da Secretaria da Fazenda.

Uma segunda análise poderia ser a do custo de cada unidade administrativa detalhado por atividade e por item. Essa é uma evolução do modelo de duas dimensões em que, além de analisar o custo da unidade por item de custo, o gestor conhece o custo de todas as atividades realizadas em cada unidade. Outra maneira seria analisar custo por item de custo aberto por atividade em cada unidade administrativa.

Vários relatórios podem ser extraídos no módulo de informações gerenciais do BCB: Custo dos recursos; Custo das atividades; Custo dos objetos de custos nos 4 níveis; Custo médio das atividades de apoio, todos por diretoria, unidade e subunidade, e Custo dos projetos desenvolvidos no Banco. 
A partir desses relatórios, algumas análises podem ser realizadas. Pode-se comparar o custo das atividades de apoio (existentes em todas as unidades administrativas do Banco) com o custo das atividades-fim por diretoria, unidade e subunidade. Com isso, é possível saber o grau de concentração dos esforços de cada unidade em suas atribuições mais importantes. Outra análise é a comparação do custo das atividades semelhantes desempenhadas por unidades distintas, permitindo aferir o grau de utilização dos recursos disponibilizados pelas unidades em atividades comparáveis. Pode-se também comparar o custo de determinadas atividades do Banco com o valor de serviços/produtos oferecidos externamente, bem como o custo dos serviços de administração de fundos e programas com as taxas de administração a serem cobradas.

Uma crítica que pode ser feita no caso do BCB tem a ver com o curto prazo destinado à implantação de um projeto com essa magnitude. Isso levou ao não aprofundamento da definição de alguns direcionadores de primeiro e segundo estágios, o que levou a um dimensionamento exagerado do objeto de custo Institucional.

Finalmente, uma limitação aos dois casos foi a não integração total, tanto conceitual como sistemática, aos subsistemas de orçamento público, financeiro, contábil e processamento de dados.

\section{Conclusões}

Duas dificuldades foram comuns aos dois casos. A primeira dificuldade foi a inexistência de experiências similares em outros órgãos governamentais brasileiros que pudessem servir de referencial. A segunda foi a multiplicidade de tecnologias e plataformas computacionais existentes, além de soluções domésticas em planilha eletrônica, o que retardou a implantação dos sistemas de custos. Houve também a necessidade de realização de alterações em alguns programas da área de Tecnologia de Informação para que a captura de dados ocorresse conforme estabelecido nos requisitos. No caso da Bahia, a utilização da plataforma web facilitou o acesso dos usuários, mas, com isso, gerou um tráfego intenso aumentando o tempo de resposta do servidor. Houve necessidade de aumentar a capacidade do servidor para atender essa maciça demanda.

As análises conduzidas nesse artigo indicam que os aperfeiçoamentos que aumentem a utilização gerencial do sistema de custos e a aderência do sistema ao plano teórico não são apenas possíveis como são necessários. Uma vez consolidada a operacionalização, é preciso, porém, perseguir a utilização gerencial do sistema de custos, sob pena de reduzir as iniciativas a simples rotinas burocráticas a serem cumpridas.

Com a implantação do ACP no Governo da Bahia e do Custeio Baseado em Atividades no Banco Central do Brasil pretende-se dotar a Administração Pública de instrumentos gerenciais de tomada de decisão ágil e eficaz. Busca-se permitir aos gestores o conhecimento do modo pelo qual sua unidade consome os recursos postos à sua disposição, estimulando assim o desenvolvimento 
de uma cultura organizacional que tenha como um de seus valores básicos a qualidade do gasto público. Possibilita ainda aos gestores orientar melhor seus esforços, alocando recursos em atividades que agreguem valor à sociedade. Isto está perfeitamente em linha com o disposto na LRF.

Um desafio para ambos os sistemas de custo é adequar-se ao Sistema de Informação de Custos do Governo Federal, em vigor a partir de março de 2010, e assim potencializar seu uso. Como parte dessa estratégia, faz-se necessário destacar a importância da mensuração de custos para a melhoria de qualidade do gasto para os gestores envolvidos. A questão central é fazer com que as informações geradas sejam úteis e apropriadas ao processo decisório.

A contribuição desse artigo é demonstrar como vem sendo implantado o sistema de custos em organizações públicas em geral no Brasil e, em particular, no Governo do Estado da Bahia e no Banco Central do Brasil. O relato desses dois estudos de caso não deve ser visto apenas como forma de compartilhar seus resultados, mas também como oportunidade de oferecer a outras organizações públicas, em qualquer esfera governamental, motivação e informações para o empreendimento de ações semelhantes.

\section{Referências}

ATKINSON, A. A. et al. Management accounting, 3ª.ed. New Jersey: Prentice Hall, 2001. 595 p.

BANCO CENTRAL DO BRASIL. O sistema de custos no Banco Central do Brasil: um estudo do caso. Brasília: BCB, Diretoria de Administração, Departamento de Planejamento e Orçamento, 2004.

BIAZZI, M. R.; BIAZZI, J. L.; MUSCAT. A. R. N. Metodologia de aperfeiçoamento de processos: estudo de casos em instituições públicas brasileiras. In: CONGRESSO DA ENANPAD, 30., 2006, Salvador. Anais... Salvador: Anpad, 2006. Disponível em: <http://www.anpad.org.br/ evento.php acao $=$ subsecao\&cod_edicao_subsecao $=149 \&$ cod_evento_edicao $=10>$. Acesso em: 22 fev. 2008.

BRASIL. Acórdão no 1.078/2004. Disponível em: <https://www.portalsof.planejamento.gov.br/.../ Relatorio_Final_da_Comissao_de_Custos.pdf.>.Acesso em: 23 mar. 2011.

. Decreto $n^{\circ}$ 6.976, de 07 de outubro de 2009. Diário Oficial da República Federativa do Brasil, Brasília, DF, 10 out. 2009.

Decreto $n^{\circ}$ 92.452, de 10 de março de 1986. Diário Oficial da República Federativa do Brasil, Brasília, DF, 12 mar. 1986.

Decreto Lei no 200, de 25 de fevereiro de 1967. Diário Oficial da República Federativa do Brasil, Brasília, DF, 27 fev. 1967.

. Lei Complementar n ${ }^{\circ}$ 101, de 04 de maio de 2000. Diário Oficial da República Federativa do Brasil, Poder Legislativo, Brasília, DF, 5 maio 2000. Seção 1, p.1

Lei n ${ }^{\circ}$ 4.320, de 17 de março de 1964. Diário Oficial da República Federativa do Brasil, Poder Legislativo, Brasília, DF, 23 mar. 1964. Seção 1, p. 2745.

.Lei $n^{\circ} 10.524$, de 25 de julho de 2002. Diário Oficial da República Federativa do Brasil, Poder Legislativo, Brasília, DF, 27 jul. 2002. 
Gestão de custos na administração publica: estudo de casos do governo da Bahia e do Banco Central do Brasil

.Lei n ${ }^{0}$ 10.707, de 30 de julho de 2003. Diário Oficial da República Federativa do Brasil, Poder Legislativo, Brasília, DF, 30 jul. 2003.

Portaria Interministerial n ${ }^{\circ}$ 945, de 26 de outubro de 2005. Diário Oficial da República Federativa do Brasil, Brasília, DF, 27 out. 2005.

CHING, H. Y. Contabilidade gerencial: novas práticas contábeis para gestão de negócios. São Paulo: Prentice Hall, 2005. 320 p.

HOLANDA, V. B.; LATTMAN-WELTMAN, F.; GUIMARÃES, F. Sistema de informação de custos na administração pública federal. Rio de Janeiro: FGV, 2010. 160p.

KAPLAN, R. S.; COOPER, R. Custo e desempenho: administre seus custos para ser mais competitivo. São Paulo: Editora Futura, 1998. 376p.

LIMA, D. V.; CASTRO, R. G. Contabilidade Pública. São Paulo: Editora Atlas, 2000. p.?

MACHADO, N.; HOLANDA, V. B. Diretrizes e modelo conceitual de custos para o setor público a partir da experiência no governo federal do Brasil. Revista de Administração Pública, v. 44, n. 4, p. 791-820, jul./ago. 2010.

MINISTÉRIO DO PLANEJAMENTO, ORÇAMENTO E GESTÃO. Comissão interministerial de custos: relatório final. Brasília, jun.2006. (Secretaria do orçamento federal) Disponível em: $<$ http:// www.portalsof.planejamento.gov.br/bib/publicacoes>. Acesso em: 05 mar. 2011.

NAKAGAWA, M. ABC: Custeio baseado em atividades. São Paulo: Editora Atlas, 1994. 95p.

NETO, J. M. S.; MELO, R. P.; PEREIRA, S. A Resultados notáveis na administração pública: avaliação de programas utilizando mapas estratégicos e o balanced scorecard. In: CONGRESSO DA ENANPAD, 30., 2006, Salvador. Anais... Salvador: Anpad, 2006. Disponível em: <http://www. anpad.org.br/evento.php?acao=subsecao\&cod_edicao_subsecao $=149 \&$ cod_evento_edicao $=10>$. Acesso em: 23 fev. 2008.

PIGATTO, J. A. M; HOLANDA, V. B.; MOREIRA, C. R; CARVALHO, F. A. A importância da contabilidade de competência para a informação de custos governamental. Revista de Administração Pública, v. 44, n. 4, p. 821-837, jul./ago. 2010.

RAUPP, F. M. Proposta de implementação do custeio baseado em atividades no legislativo municipal. Revista Pensar Contábil, v. 12, n. 49, p. 23-30, set./dez. 2010.

REZENDE, F.; CUNHA, A.; CARDOSO, R. L. Custos no setor público. Revista de Administração Pública, v. 44, n. 4, p. 789-790, jul./ago. 2010.

SANTANA, E. W. F. et al. A eficácia orçamentária municipal: os impactos produzidos pela Lei de Responsabilidade Fiscal. In: CONGRESSO DA ENANPAD, 31., 2007, Rio de Janeiro. Anais... Rio de Janeiro: Anpad. 2007. Disponível em: <http://www.anpad.org.br/evento. php $2 \mathrm{acao}=$ subsecao\&cod_edicao_subsecao $=280 \&$ cod_evento_edicao $=33>$. Acesso em: 20 fev.2008.

SANTOS, S. R. T.; ALVES, T. W. O impacto da Lei de Responsabilidade Fiscal nos orçamentos: uma analise do desempenho financeiro nos municípios de Rio Grande do Sul de 1997 a 2004. In: CONGRESSO DA ENANPAD, 31., 2007, Rio de Janeiro. Anais... Rio de Janeiro: Anpad Disponível em: $<$ http://www.anpad.org.br/evento.php?acao=subsecao\&cod_edicao_subsecao=280\&cod_evento_edicao $=33>$. Acesso em: 20 fev.2008.

SILVA, L. I. S. et al. Orçamento público: um natural sistema de custos. Revista de Contabilidade da UFBA, v. 2, n. 1, p. 52-66, jan/abr. 2008. 
SILVA, B. F.; ROCHA, E. S. Uma contribuição para a implantação de custos no setor público: estudo de caso: Embrapa e BACEN. In: CONGRESSO BRASILEIRO DE CUSTOS, 16., 2007, Fortaleza. Anais... Fortaleza: ABcustos 2007

SLOMSKI, V.et al. A demonstração do resultado econômico e sistemas de custeamento como instrumentos de evidenciação do cumprimento do princípio constitucional da eficiência, produção de governança e accountability no setor público: uma aplicação na Procuradoria-Geral do Município de São Paulo. Revista de Administração Pública, v. 44, n. 4, p. 933-937, jul./ago. 2010.

TONETO, Jr., R.; MENEZES, R. T. O impacto da Lei de Responsabilidade Fiscal sobre as despesas municipais para os municípios do Sudeste. In: CONGRESSO DA ENANPAD, 30., 2006, Salvador. Anais... Salvador: Anpad, 2006. Disponível em: <http://www.anpad.org.br/evento. php acao $=$ subsecao\&cod_edicao_subsecao $=149 \&$ cod_evento_edicao $=10>$. Acesso em: 26 fev. 2008.

WERNECK, S. S. Metodologia de custeio baseado em atividades implementadas no banco central do Brasil: uma análise quanto ao uso das informações, objetivos almejados, benefícios esperados e expectativas levantadas. In: CONGRESSO DA ENANPAD, 30., 2006, Salvador. Anais... Salvador: Anpad, 2006. Disponível em: <http://www.anpad.org.br/evento. php acao $=$ subsecao\&cod_edicao_subsecao $=149 \&$ cod_evento_edicao $=10>$. Acesso em: 28 fev. 2008 .

Submetido em 15 de fevereiro de 2010 Aprovado em 02 de junho de 2011 